\title{
Educación, estética y régimen visual en la configuración del sistema educativo argentino*
}

\section{Investigaciones \\ Revista Colombiana de Educación, N. 63. Segundo semestre de 2012 Bogotá, Colombia.}

//Education, aesthetic and visual

regime in the configuration of the

Argentine educational system

\section{//Estética, educação e sistema \\ visual na configuração do sistema \\ educacional argentino}

María Silvia Serra**
Recibido: 05/07/2012 Evaluado: 27/09/2012

\begin{abstract}
Este artículo se inscribe dentro de los alcances de la investigación doctoral titulada "Cine, escuela y discursopedagógico " efectuada en la facultad Latinoamericana de Ciencias Sociales.

Doctora en Ciencias Sociales de la Flacso. Magister en Ciencias Sociales de la Universidad Nacional de Litoral. Profesora de la facultad de humanidades y artes de la Universidad Nacional de Rosario (Argentina).

Correo electrónico: silserra@fibertel.com.ar
\end{abstract}

\section{Resumen}

En la configuración de las prácticas escolares es posible reconocer una serie de disposiciones de neto corte visual, que no solo delimitan una particular relación entre el ver y el conocer, sino que otorgan cierto privilegio al sentido de la vista por encima de otros registros sensibles. Estas disposiciones son parte de la función estetizante que cumplió el sistema educativo argentino, donde la educación de los sentidos constituyó una preocupación que combinó un régimen de verdad, ligado al conocimiento, con la producción de sensibilidades específicas, donde verdad, belleza y moralidad eran parte de la misma operación.

\section{Abstract}

In the configuration of the school practices we can recognize a series of clear-cut visual features that not only delimit a particular relation between seeing and knowing, but also grant certain privileges to the sense of sight above other sensitive perceptions. These features are part of the aestheticizing function of the Argentine educational system whose education of the senses was a concern that combined a regime of truth, related to knowledge, with the production of specific sensitivities in which truth, beauty and morality were part of the same operation.

\section{Resumo}

Na configuração das práticas escolares é possível reconhecer uma série de visuais corte provisões líquidas, que não só definem uma relação particular entre ver e saber, mas certo privilégio concedido ao sentido da visão acima de outros registros sensíveis. Estas disposições são parte da estetização função que transformou o sistema de ensino da Argentina, onde a educação dos sentidos era uma preocupação que combinou um regime de verdade, do conhecimento relacionado com a produção de sensibilidades específicas, onde a beleza, verdade e moralidade eram parte da mesma operação.

\section{Palabras Clave}

Sistema educativo argentino - estética - régimen visual educación de los sentidos.

\section{Keywords}

Argentine educational system - aesthetics - visual regime sense education.

\section{Palavras chave}

Sistema educativo argentino - estética - régimen visual - educação dos sentidos. 
"En el intercambio mundial vence el que, a igualdad de materia prima, ofrece el objeto más bello".

Educación estética

El Monitor de la Educación 484, abril de 1913

Este escrito parte de una hipótesis: en la configuración de las prácticas escolares es posible reconocer una serie de disposiciones ligadas al aprendizaje, a los métodos de enseñanza, al uso del espacio, a concepciones pedagógicas, a sentidos sobre el arte, a dispositivos mecánicos de neto corte visual, que no solo delimitan una particular relación entre el ver y el conocer, sino que otorgan cierto privilegio al sentido de la vista por encima de otros registros sensibles. Estas disposiciones y dispositivos son parte de la función estetizante que cumplió el sistema educativo argentino, donde la educación de los sentidos constituyó una preocupación que combinó un régimen de verdad, ligado al conocimiento, con la producción de sensibilidades específicas, donde verdad, belleza y moralidad eran parte de la misma operación.

Ahora bien, para desplegar y desarrollar esta hipótesis necesitamos ensayar un abordaje en clave estético de la configuración de la escuela argentina, combinar la mirada pedagógica con una mirada analítica que atienda las huellas en las formas, los sentidos construidos alrededor del gusto, las marcas que proponen una sensibilidad específica. Pero, siendo la estética un saber con tradiciones específicas y desarrollos propios como disciplina, ¿qué posibilidades ofrece para interrogar los elementos del discurso pedagógico? ¿Es posible ensayar un análisis en clave estético que atienda el régimen de visibilidad presente en un momento particular de una configuración discursiva?

En el presente trabajo abordaremos algunas claves conceptuales que circunscriban y configuren este territorio de indagación, atendiendo especialmente el modo en que se intersectan prácticas y discursos pedagógicos con registros propios de la cultura que los incluye. 


\section{Acerca de los saberes propios de la reflexión estética}

La estética como disciplina, como objeto de otras disciplinas, como dimensión de análisis o como saber interdisciplinario viene siendo objeto de debates. Existe una amplia tradición de estudios que ponen en el centro de sus preocupaciones al arte y a la belleza, configurando así a la reflexión estética como la que, desde diferentes aproximaciones que van desde la filosofía analítica y las teorías del lenguaje a aproximaciones idealistas, deconstructivistas, pragmatistas, etc., "miran, desde su perspectiva metodológica, al arte y a lo bello" (Mandoki, 2006a, p. 15, cursivas en el original).

Sin embargo, las definiciones sobre qué es arte y qué no lo es y qué entendemos por belleza vienen siendo objeto de reflexiones que enfatizan su carácter histórico y contingente, además de su inscripción en un orden más amplio de legitimación de un orden social (Eagleton, 2006). Estas discusiones, presentes en los análisis filosóficos y epistemológicos de los saberes propios de la estética, también dejan ver tensiones entre quienes conciben que lo bello es atributo de los objetos, habilitando así a la estética como reflexión sobre el arte y su potencia, y quienes ponen énfasis en la subjetividad de quienes se enfrentan a esos objetos, atendiendo a las condiciones de posibilidad de ser afectados por acontecimientos u objetos de su entorno de los seres humanos (Mandoki 2006a) ${ }^{1}$.

Sin embargo, la transformaciones que ha sufrido el campo del arte y de la representación, ligadas al desarrollo de distintos medios tecnológicos como a la misma idea de reproducción mecánica en el campo de la cultura -tal como lo enfatizaran, en diferentes sentidos, autores como Dewey y Benjamin, en los inicios del siglo XX- habilitan otros modos de entender y poner en juego en el pensamiento lo que entendemos por estética, no solo por el carácter contingente que tienen los términos arte y belleza, sino fundamentalmente por la apertura a otras dimensiones de la vida cotidiana, como la arquitectura, la cocina, los lenguajes masivos, etc., y ponen en evidencia que el vínculo entre estética y realidad excede el campo específico de las manifestaciones artísticas de la cultura. Lo que se pone

\footnotetext{
Mandoki reclama otro estatuto para el saber sobre la estética señalando que de lo que se trataría "es de partir de la filosofía y construir un corpus interdisciplinario que permita incorporar diversas metodologías pertinentes a una visión integral del fenómeno estético. (...) Dado que la estética no es una cuestión exclusivamente filosófica sino cultural, social, comunicativa, política, económica, histórica, antropológica, cognitiva, semiótica, y aun neurológica, sería menester abordarla con un trabajo multidisciplinario puesto que varias de estas disciplinas se traslapan al enfocar esta problemática" (2006a, p. 16).
} 
en juego es una reflexión sobre las posibilidades del ser humano de ser permeables a su entorno, poniendo en relevancia la cuestión de lo sensible, $y$ apuntando a responder interrogantes sobre cuáles son las condiciones de posibilidad de la sensibilidad humana y cuáles son sus manifestaciones (Mandoki, 2006a, p. 81).

Katya Mandoki, en su amplio trabajo sobre los saberes estéticos (2006 y y 2006b) define a la estética como el estudio de la condición de estesis, entendiendo por esta a la "sensibilidad o condición de abertura, permeabilidad o porosidad del sujeto al contexto en que está inmerso" (2006a, p. 67, cursivas en el original). Mandoki señala a la estesis como el efecto de la condición sensible del ser humano, y apunta al estudio del modo en que los diferentes registros de lo sensible se imprimen en la subjetividad.

En consonancia con esta definición Frigerio y Diker, entendiendo a la estética como fábrica de lo sensible, en la clave de Rancière, proponen atender a la institución de un mundo sensible común que vaya más allá de las sensaciones y reglas del gusto, para atender modos de conocer, de repartir/distribuir y de inscribir (Frigerio y Diker, 2007, P. 9). De la mano de estas autoras es que ingresamos entonces al cruce entre estética y educación: si la estética es definida como el estudio de la producción de sensibilidad, en el campo educativo necesitamos atender al modo en que los procesos de transmisión operan con capacidad de imprimir, de dejar huella, de afectar. Por su capacidad de producir identidades colectivas, los procesos educativos han sido señalados como claves en la producción y reproducción del orden social, de lo correcto e incorrecto, de un determinado sentido del gusto, de la belleza y del placer, aunque ha sido la categoría "ideología" la que ha predominado. A este respecto, Mandoki señala:

La metáfora de "cemento social" se ha utilizado a menudo para explicar la función de la ideología en la sociedad. La ideología, sin embargo, aglutina a la gente menos por su importe informativo (semiótico) que por el importe emocional o la carga afectiva que es capaz de reclutar y suscitar (estética), menos por una operación denotativa que por la connotativa. Hay un componente estético en el modo en que se construye y propaga la ideología, y su función cohesiva es resultado de movilizar a la estesis con que se genera la adherencia y la identificación imprescindibles para la vinculación de los sujetos entre sí y con las instituciones (2006a, pp.154-155). 
La idea de estética como "cemento social" puede ser útil para volver a mirar los procesos educativos y ampliar la comprensión de cómo operan no solo en clave de transmisión de conocimientos, sino fundamentalmente en su capacidad de instituir sensibilidades y matrices de percepción.

\section{Estética y regímenes visuales: el registro escópico}

Asomarnos a los sistemas educativos modernos en clave estética puede resultar una tarea muy amplia, por lo que nos concentraremos, en este trabajo, en aquellos procesos presentes en la educación escolar que apuntan fundamentalmente a la institución de un régimen especifico de visualidad. Esta focalización responde a una doble razón: por un lado, al reconocimiento de una importante serie de dispositivos ligados al sentido de la vista que operan en la escena escolar; y, por otro, a la relevancia que las reflexiones sobre la visualidad vienen teniendo en diversos desarrollos contemporáneos, invitándonos a genealogizar su emergencia y sus sentidos en los tiempos de configuración del sistema educativo.

En la reflexión estética, la preocupación por el registro visual ha sido central. Mandoki lo define como registro escópico, entendido del siguiente modo:

El término de "escópica" deriva del griego skopía, que significa observar, ver, mirar. Por ello, el registro escópico se refiere a la puesta a la vista a través de la construcción de sintagmas de componentes espaciales, visuales, objetuales como vestuario, utilería, maquillaje y escenografía (setting en términos de Goffman) para lograr efectos en la sensibilidad (Mandoki, 2006b, p. 33).

Destacamos en esta definición el término poner a la vista, una tarea tan propia de la acción de la escuela que puede pasar desapercibida, y que va desde la existencia del pizarrón y la configuración del aula alrededor de este hasta el principio de observación como modo de conocer.

Ahora bien, las preocupaciones por la visualidad o por lo que se pone a la vista exceden el campo de los estudios estéticos. Los conceptos de régimen de visibilidad o matriz ocularcéntrica (Ferrer, 1996), regímenes escópicos (Jay, 2003; Brea, 2007; Antelo, M.: 2005), así como las expresiones "formas de lo visible" (Didi-Huberman, 2006), "modos de ver" (Berger, 2006), o la más generalizada "formas históricas de la mirada" vienen teniendo desarrollo propio en las relfexiones filosóficas, sociológicas y de la teoría cultural. Todos ellos remiten al reconocimiento de una matriz visual que participa de la configuración tanto subjetiva como colectiva de una so- 
ciedad y sus miembros, matriz que está presente en las relaciones que una época establece entre lo que se ve y lo que se mira (el ojo y el objeto de la mirada), y de la que son parte tanto los artefactos que miran por los ojos como los que dan a ver.

En las últimas décadas, donde los desarrollos electrónicos ampliaron la cantidad y el registro de las imágenes e inundaron la vida cotidiana, los desarrollos teóricos sobre la visualidad o la cultura visual han crecido mucho. Muchos de los estudios sobre la relación imagen/sociedad encontraron su lugar bajo el nombre de estudios visuales (Brea, 2005; Richard, 2006). Más allá de los debates sobre su estatuto epistemológico, estas reflexiones señalan la existencia de un régimen dominante de visibilidad que se remonta a por lo menos dos siglos, donde imagen, verdad y poder se combinan en la producción de mundo que vivimos, y que permite situar una matriz ocularcéntrica:

En los últimos dos siglos la obligación de ver no viene determinada por la ampliación y el mejoramiento de una capacidad fisiológica, ni por la decadencia de la alta cultura ni por los avances tecnológicos, sino porque el régimen de visibilidad dominante -régimen político entonces- predispone a creer lo que en su interior se ve. Hacer ver la verdad: es este el objetivo de esa voluntad de poder, que quiere impedir cualquier otro derecho de visión y para ello busca apropiarse incluso de la más nimia célula de visión humana. Se trata de los que algunos autores Ilaman ocularcentrismo, sistema de orientación y coerción visual efectuado a través de las actividades visuales cotidianas (Ferrer, 1996, p. 30).

En la configuración de los sistemas educativos modernos, mucho se ha insistido en la centralidad de la palabra y del lenguaje verbal, dado que en clave de conocimientos han sido la lectura, la escritura y las operaciones básicas de cálculo los contenidos centrales de la alfabetización escolar. Sin embargo, desde sus inicios es posible encontrar una serie de preocupaciones ligadas a la educación estética, a la vez que un conjunto de prescripciones estéticas sobre el orden escolar. En ambos conjuntos es notable la preeminencia de una matriz visual, presente en una serie de instrumentos y prácticas ligados a la institución de unos específicos modos de ver: las láminas, el microscopio, los museos escolares, las "linternas mágicas", el cinematógrafo, la disposi- 
ción escenográfica de los objetos en el espacio del aula, la decoración de los muros, la observación directa a través de paseos son indicios de un orden visual que merece ser tenido en cuenta. En ellos se evidenció una preocupación alrededor de lo que se daba a ver y a mirar donde es posible leer la matriz ocularcéntrica de la época.

\section{Educación estética en la escuela}

Las preocupaciones por la educación estética se hacen presentes tempranamente en los tiempos de configuración del sistema educativo argentino. Ligadas fundamentalmente al arte y a la belleza, y nominadas como "la educación de los sentidos", "el arte en la educación", o, directamente, como "educación estética", plantean la importancia de que la educación escolar trascienda los marcos positivistas y también se ocupe de la educación "del espíritu".

En la publicación El Monitor de la Educación Común, órgano de difusión de las bases del orden escolar del Estado argentino, nos encontramos con que sistemáticamente se afirma la necesidad de educar los sentidos, refinar el gusto, "impresionar el espíritu", colocando al lado de la educación científica a la educación artística. Se afirma que: "Hay conveniencia en que, a la inflexibilidad de la demostración que ocupa la razón, se agregue siempre la emoción de la belleza resultante de la contemplación de la naturaleza y de la vida" (reseña del $4^{\circ}$ Congreso Internacional de la Enseñanza del Dibujo y de las Artes Aplicadas a la Industria. El Monitor de la Educación, 649, enero de 1912).

Serán los cuadros y las láminas, la decoración de las paredes, así como la enseñanza del arte y el ejercicio de su desarrollo -fundamentalmente del dibujo- los que serán instrumentos de inculcar la noción de belleza en el niño, de dejar en él impresiones indelebles, atendiendo a la permeabilidad del espíritu infantil y juvenil y a su capacidad de ser afectado por estímulos externos cuidadosamente presentados:
¿Y no es natural que en presencia de la mono- tonía de blancas y des- nudas paredes, y de la enseñanza del dibujo con frecuencia plasma- da en formas muertas, tengan la vista y el es- píritu verdaderamente hambre de frescor, color y animación? (Principios artísticos de la escuela popular. El Monitor de la Educación Común, 352, junio de 1902, p. 636).

Alrededor de las prescripciones sobre el arte y la belleza, y en clave tanto estética como cognitiva, se despliegan consideraciones sobre la necesidad de la educación de los sentidos. Entre ellos, se hace explíci- 
to que la vista y el oído son considerados "nobles" y de quienes depende la inteligencia, siendo el resto "directamente más útiles a la vida animal". Por ello abundan los ejercicios para cultivar y educar el sentido de la vista que van más allá de los fines artísticos, atendiendo especialmente a la forma y el color. Se postula como necesario el enseñar a ver bien, procurar el "buen juicio del ojo" (El arte en la educación. El Monitor de la Educación Común, 357, noviembre de 1902).

La necesidad de la educación de los sentidos va más allá del gusto, y tiene que ver con el desarrollo de operaciones racionales para conocer:

Es espantoso comprobar hasta qué punto nos engañan nuestros sentidos y gracias a qué esfuerzos llegamos a conducirlos a sensaciones exactas. Nuestra razón es un general que tiene a sus órdenes cinco ayudantes, siempre dispuestos a transmitirle partes falsos, que él ha de verificar a cada momento (Prevóst, Gabriel: La educación de los sentidos. El Monitor de la Educación Común, 330, agosto de 1900).

El "jucio del ojo", en este sentido, no es solo estético, sino que implica un régimen de verdad específico, donde ver y conocer se vinculan, pero mediados por una regulación específica. ¿Es posible despejar lo estético de lo cognitivo en estas operaciones? ¿Acaso la metáfora de un "cemento social" en clave estética, enunciada más arriba, no podría englobar formas y contenidos de la transmisión escolar y a la vez ser parte de su éxito? Atendamos al siguiente ejemplo. En un artículo de El Monitor de la Educación denominado "Lecciones al aire libre. Estética y patriotismo" se invita a visitar la estatua de un prócer en alguna plaza cercana. Se propone, a través de la observación "directa" de la estatua o busto, recuperar su vida, su biografía, su gesta. Pero también se invita a observar el ámbito donde el monumento está, su emplazamiento, su entorno, etc.

Este orden estético no se aleja ni del orden moral fundante del sistema educativo ni de los principios higienistas que le fueron afines. Al mismo tiempo que se pregona la belleza, se plantea que "amar la belleza es amar la bondad; ser capaz de percibir la armonía de la línea y del color es un antecedente para percibir la exquisita armonía del gesto generoso, bueno y noble" (Educación estética. El Monitor de la Educación, 484, abril de 1913). 
Realizando un correlato ajustado entre el principio de belleza y una descripción de lo que representa en términos prácticos, los postulados estéticos y los morales se vuelven comunes:

En cuanto a la decoración de las aulas y corredores, los principios directores serán la sencillez y la honradez. Nada de floreos exagerados; sobre todo, nada de "trampantojos"; únicamente la verdad, para las paredes y el mobiliario escolar; colores sanos y discretos, frisos y guirnaldas; en fin, grabados, estampas, etc. (J. Molitor: El arte en la escuela y la cultura estética. El Monitor de la Educación Común, 492, p. 333, diciembre de 1913).

Si los planteos estéticos tienen un límite es justamente el de no contradecir los otros rasgos que el sistema educativo tuvo en su horizonte:

Nadie podrá decir con certeza si, en la educación estética del niño, tiene más importancia la vista de una obra de arte maravillosa que detiene su mirada sorprendida, o el felpudo que halla en la puerta $y$, obligándole a repasarse los pies antes de entrar a la escuela, le insinúa sencilla y silen- ciosamente una lección de aseo, de cultura y de respeto al local en que penetra (Fusoni, Fernando: El arte en la escuela. El Monitor de la Educación, 470, p. 247, febrero de 1912).

\section{El registro visual para conocer}

Tal como señalamos, en la configuración del sistema educativo argentino, además de las preocupaciones de explícito corte estético, nos encontramos con prescripciones sobre lo visual, lo que se puede y debe ver y lo que se ofrece a la mirada que merecen ser tenidos en cuenta en este registro.

La inclusión en la escuela de imágenes fabricadas para ser usadas en la enseñanza está presente desde los comienzos del siglo XX. Láminas, fotografías, vistas cinematográficas, microscopios, lupas, telescopios son objetos de atención por su potencia para ampliar la mirada y profundizar lógicas de conocimiento.

En este régimen el ver y el conocer se engarzan al punto que lo que se sabe se sostiene en lo que se ve, por lo que el registro escópico se sostiene sobre una "episteme escópica": la estructura abstracta que determina el campo de lo cognoscible en el territorio de lo visible (Brea, 2007, p. 146). Quizá aquí sea necesario ampliar y complejizar la definición de régimen escópico: 
Bajo tal "régimen escópico" se definen, doblemente, tanto [1] un conjunto de "condiciones de posibilidad" -determinado técnica, cultural, política, histórica y cognitivamente- que afectan a la productividad social de los "actos de ver", como [2] un sistema fiduciario de presupuestos y convenciones de valor y significancia, que definen el régimen particular de creencia que con las producciones resultantes de dichos actos es posible establecer, para el conjunto de agentes que intervienen en los procesos de su gestión pública, ya sea como receptores, ya como productores activos que disponen sus actos en el universo lógico de los enunciados y actuaciones posibles en su contexto (Brea, 2007, pp. 150-151).

El conjunto presentado de imágenes tendrá que ser estudiado, entonces, en su "artificialidad": las imágenes, entendidas no como producto sin "productor", sino como efecto de un devenir, como resultado de una apelación a la mirada, donde el "sujeto" que convierte al mundo en imagen al producirla es parte de una trama social. Imágenes que son, a la vez, efecto de una mirada y ofertas a la mirada. Por otro lado, cada uno de los tipos de imágenes mencionados tiene rasgos que le son propios, tanto en relación a su configuración semiótica como a su emplazamiento social, por lo que analizarlos en clave estética nos obligará a atenderlos en su especificidad.

Tomemos el ejemplo de las vistas cinematográficas, de las que es posible apoyarnos en estudios ya realizados (Serra, 2011). Desde la emergencia del cine en el escenario de las invenciones modernas, el discurso pedagógico se ocupa de él, pero distinguiendo dos facetas diferentes; el hecho de que distrae y enseña. Las valoraciones pedagógicas sobre el cinematógrafo como medio de entretenimiento son muchas, variadas y en algunos casos, contradictorias. Hay quienes lo denostan y quienes lo celebran, aunque la constante entre pedagogos y maestros es Ilamar la atención sobre los peligros morales ${ }^{2}$ que encierra, aun cuando se lo reconozca como acontecimiento técnico y cultural sin precedentes. Pero lo importante a señalar aquí es que, más allá de la opinión que merezca el cinematógrafo, el discurso pedagógico se empeña en delimitar un tipo de cinematografía que

2 Cabe aclarar que en la postulación de peligro moral se pone en juego el marco higienista propio de la época. 
incluye tanto un conjunto delimitado de materiales, un tipo de producción de los mismos, y unas reglas y principios para su uso en la escuela, estableciendo así un dominio específico, que implica unos saberes y unas prácticas propias ${ }^{3}$.

Uno de los pocos materiales que se han conservado de esta época, y que puede ser tomado como ejemplo para poner en juego lo que se daba a ver, es La mosca y sus peligros. Fechada en 1920, este material fue recientemente editado en $C D$ como parte de una política de divulgación de material cinematográfico mudo argentino del INCAA (Instituto Nacional de Cine y Artes Audiovisuales), el Gobierno de la Ciudad de Buenos Aires y el Museo del Cine Pablo Ducrós Hicken 4 .

Realizado por Eduardo Martínez de la Pera y Ernesto Gunche, dos importantes cineastas argentinos, La mosca y sus peligros, de 35 minutos de duración, comienza con la explicitación de su objetivo: "El principal objetivo de esta película es divulgar ante el público, conocimientos que

3 Narodowski señala que "la conformación de la pedagogía moderna es justamente ese proceso en el que el discurso pedagógico se convierte en un campo más o menos previsible, con reglas de formación más o menos constantes y con mecanismos discursivos usualmente invariables" (Narodowski, 1999). La intención de asimilar el cine a un dominio específico, con reglas y mecanismos ya perfilados, muestra la dificultad de interrogarse a sí mismo frente a un artefacto "extranjero" a la cotidianidad de la escuela.

4 Primera Antología del Cine Mudo Argentino. INCAA, Gobierno de la Ciudad de Buenos Aires y el Museo del Cine Pablo Ducrós Hicken, Buenos Aires, s. $f$ en general son solo del dominio de los investigadores". En seguida, el filme hace una presentación general de la mosca, de su morfología, de sus partes, de sus costumbres, enfatizando su capacidad para amplificar la circulación de microbios y los peligros que estos implican en la vida cotidiana. Haciendo uso de imágenes impresionantes de bebés desnutridos y enfermos por contraer enfermedades a través de la circulación de moscas entre basura y chupetes o biberones, apela al sensacionalismo directo y despliega una serie de prácticas de higiene y cuidado en tono de divulgación.

Aunque toda la película conserva un tono realista, enfatizado por la terminología científica, el registro de imágenes resulta paradojalmente construido. La mosca en presentada no en su ambiente natural, sino a través de los procedimientos del laboratorio, donde la cámara muestra, desde su entorno, los procedimientos de cambio de lentes del microscopio, el modo en que se caza una mosca con una botella, el modo en que se la mata y se la ensarta con una aguja, hasta el modo en que el personal de laboratorio se prepara para operar sobre el insecto colocándose una gorra en la cabeza. Posteriormente, se individualizan tipos de moscas con sus nombres científicos, y se las presenta una a una, con sus características morfológicas, aisladas y amplificadas. Los distintos tipos de moscas son mostrados atravesados por un alfiler, so- 
bre un fondo artificial y con la imagen recortada en un círculo. Las escenas cotidianas que el filme incluye poseen un alto contenido educativo en relación con cómo proceder (resulta llamativa la escena donde una empleada doméstica lleva un vaso de leche a una mujer con apariencia de "patrona", pero al descubrir que dentro de la leche hay una mosca mete sus dedos y la retira, sin ser vista, y entrega el vaso a su destinataria). El filme no duda en introducir otros dispositivos como el microscopio, propios del régimen de verdad que liga ver a conocer.

Más allá de su divulgación dentro o fuera de la escuela, esta película participa del enclave pedagógico propio de la mirada escolar. Por un lado, confluye la idea de "divulgación de procedimientos científicos" con la intención educativa, mostrando la articulación de discurso pedagógico, médico e higienista propio de la época. El segundo lugar, pone en juego la centralidad del sentido de la vida para el desarrollo del aprendizaje (o principio de la "intuición": entendiendo por este mirar, fijar los ojos, observar, contemplar, examinar). En tercer lugar, se hacen eco de la necesidad de educar los sentidos y de hacer de la observación un ejercicio, reafirmando el vínculo entre ver y saber. Por último, la importancia otorgada tanto a las imágenes de microscopio como al cine mismo en las tecnologías de la visión y en su creciente valor pedagógico.

La creciente centralidad del papel de la escuela en la transmisión de formas legitimadas de conocer y su expansión como institución otorgan un particular estatuto a la imagen: la hacen pública y común, al ser compartida por todos los alumnos a la vez. El cinematógrafo conserva esta dimensión común -la de ser proyectada para todos, y luego recuperada- y a su vez la amplía, al potenciarse con lo que representaba culturalmente: un lenguaje masivo, de amplia circulación en la población.

En este ejemplo es posible ver cómo se intersectan propuestas estéticas, regímenes de verdad, prescripciones morales e higienistas y didáctica de la imagen. Se vuelve necesario entonces pensarlos como parte de un registro escópico más amplio, al mismo tiempo de que atender a su función de ser "cemento" social, por su capacidad de imprimir identidades colectivas. 


\section{Referencias}

Antelo, M. (2005). El apetito del ojo. Bogotá: CID, Cuadernos del Cid.

Berger, J. (2006) Modos de ver. Barcelona: Gustavo Gili.

Brea, J. (2005). Los estudios visuales: por una epistemología política de la visualidad. En Brea, J. L. (Ed.). Estudios visuales. La epistemología de la visualidad en la era de la globalización (pp. 5-15). Barcelona: Akal.

Didi-Huberman, G. (2006). Lo que vemos, lo que nos mira. Buenos Aires: Manantial.

Eagleton, T. (2006). La estética como ideología. Madrid: Trotta.

Ferrer, C. (1996). Mal de ojo. El drama de la mirada. Buenos Aires: Colihue.

Frigerio, G. \& Diker, G. (Comp.). (2007). Educar: (sobre) impresiones estéticas. Buenos Aires: Del Estante.

Jay, M. (2003). Campos de fuerza. Entre la historia intelectual y la crítica cultural. Buenos Aires: Paidós.

Mandoki, K. (2006a). Estética cotidiana y juegos de la cultura. Prosaica I. México: Siglo XXI.

Mandoki, K. (2006b). Prácticas estéticas e identidades sociales. Prosaica II. México: Siglo XXI.

Narodowski, M. (1999). Infancia y poder. Buenos Aires: Aique.

Richard, Nelly (2006). Estudios Visuales y políticas de la mirada. En Dussel, Inés y Gutiérrez, Daniela (comps.): Educar la mirada. Políticas y pedagogías de la imagen. Buenos Aires: Flacso/Manantial/Fundación OSDE.

Serra, M. (2011). Cine, escuela y discurso pedagógico. Articulaciones, inclusiones y objeciones en el siglo XX en Argentina. Buenos Aires: Teseo. 